\title{
Solanum lasiocarpum L. Extract as Green Corrosion Inhibitor for A3 Steel in 1 M HCl Solution
}

\author{
Xia Wang*, Huan Jiang*, Dai-xiong Zhang, Li Hou, Wen-jie Zhou
}

School of Material Science and Engineering, Southwest Petroleum University, Chengdu 610500, People's Republic of China

*Email: swpi_wx@126.com, jiangqingze6379@163.com

doi: $10.20964 / 2019.02 .06$

Received: 3 August 2018 / Accepted: 28 November 2018 / Published: 5 January 2019

\begin{abstract}
An extract of Solanum lasiocarpum L. (SL) was characterized and tested for its potential anticorrosion effect on $\mathrm{A} 3$ steel in a $1 \mathrm{M} \mathrm{HCl}$ solution using weight loss analysis, potentiodynamic polarization measurements, electrochemical impedance spectroscopy, Fourier transform infrared spectroscopy and scanning electron microscopy (SEM). The electrochemical and weight loss results revealed that the SL extract was an efficient corrosion inhibitor with an inhibition efficiency of up to $93.31 \%$ at a concentration of $1 \mathrm{~g} / \mathrm{L}$, which was further confirmed by SEM observations. The adsorption process mainly comprised physisorption and chemisorption (comprehensive adsorption), and obeyed the Langmuir model. The SL extract is a mixed inhibitor that predominantly suppresses the cathodic reaction.
\end{abstract}

Keywords: Solanum lasiocarpum L., Plant-based corrosion inhibitor, Adsorption, Electrochemical FULL TEXT

(C) 2019 The Authors. Published by ESG (www.electrochemsci.org). This article is an open access article distributed under the terms and conditions of the Creative Commons Attribution license (http://creativecommons.org/licenses/by/4.0/). 